\title{
Active Thermal Control of Power Electronic Modules
}

\author{
Dustin A. Murdock, Jose E. Ramos Torres, Member, IEEE, Jeffrey J. Connors, and Robert D. Lorenz, Fellow, IEEE
}

\begin{abstract}
Active thermal control techniques make it feasible to regulate the steady state and transient thermal-mechanical stress in power electronic modules for applications such as motor drives. Online junction temperature estimation and manipulation of the switching frequency and current limit to regulate the losses are used to prevent overtemperature and power cycling failures in insulated gate bipolar transistor (IGBT) power modules. The techniques developed in this work are used to actively control the junction temperature of the power module. This control strategy improves power module reliability and increases utilization of the silicon thermal capacity by providing sustained operation at maximum attainable performance limits.
\end{abstract}

Index Terms-Active thermal control, loss control, operation in limits, power cycle control, reliability control.

\section{INTRODUCTION}

I NSULATED gate bipolar transistor (IGBT) power modules are used extensively in industry, power electronics, and traction applications [1]. It is necessary to develop more reliable power modules to satisfy the demands of these applications. In order to do this, a thermal-mechanical approach to reducing stresses within the power module has been proposed. By actively controlling the thermal operating performance, potentially damaging stresses in the module can be avoided. At the same time, the overall power conversion performance of the module increases, because it is able to "safely" operate continuously at the maximum allowable temperature and temperature cycle limits.

Previous research has identified several types of failures related to IGBT power modules and has begun to address means to mitigate such failures. The most common failures

Paper IPCSD-05-078, presented at the 2004 Industry Applications Society Annual Meeting, Seattle, WA, October 3-7, and approved for publication in the IEEE TRANSACTIONS ON INDUSTRY APPLICATIONS by the Industrial Power Converter Committee of the IEEE Industry Applications Society. Manuscript submitted for review October 1, 2003 and released for publication December 5, 2005. This work was supported by the ERC Program of the National Science Foundation under Award EEC-9731677 and by the Wisconsin Electric Machines and Power Electronics Consortium (WEMPEC) of the University of Wisconsin, Madison.

D. A. Murdock was with the Department of Electrical and Computer Engineering, University of Wisconsin, Madison, WI 53706 USA. He is now with the Development Department, Powercorp Pty. Ltd., Darwin, NT 0801, Australia (e-mail: damurdock@ hotmail.com).

J. E. Ramos Torres was with the Department of Electrical and Computer Engineering, University of Wisconsin, Madison, WI 53706 USA. He is now with Cooper Vision, Juana Diaz, PR 00795 USA (e-mail: jramos@ ocularsciences.com).

J. J. Connors was with the Department of Electrical and Computer Engineering, University of Wisconsin, Madison, WI 53706 USA. He is now with Omnitech Robotics, Englewood, CO 80110 USA (e-mail: jjconnors@ gmail.com).

R. D. Lorenz is with the Department of Electrical and Computer Engineering, University of Wisconsin, Madison, WI 53706 USA (e-mail: lorenz@engr. wisc.edu).

Digital Object Identifier 10.1109/TIA.2005.863905

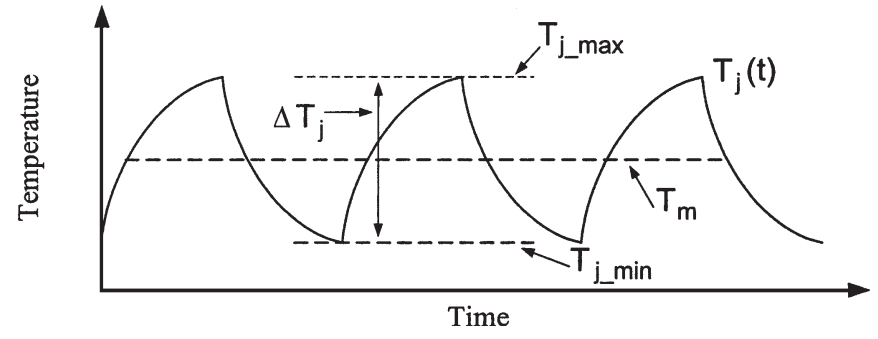

Fig. 1. Typical IGBT average junction temperature profile [5].

occur between the wire-bond-to-silicon, silicon-to-direct-bondcopper (DBC), and DBC-to-baseplate connections and are all likely regions for thermal-overtemperature- and thermalcycling-induced failures [2]. The focus of this research is to improve the reliability of power electronics by limiting thermal and thermal-mechanical stresses in the module. This work is meant to extend prior work [3], which controlled against overtemperature, to now also include power cycling failures by extending the method for actively manipulating the IGBT losses [4]. The active thermal control techniques developed in this work are also designed to be extended to thermal and thermal-mechanical stress regulation in other power module interfaces and components in the drive. These control methods should also be useful to improve reliability for general power electronic applications that operate with fluctuating loads. The control laws for a region-based control structure will be discussed with experimental results used to help illustrate the effectiveness of these control algorithms [5].

Another component that is necessary for successful implementation of active thermal control is high-fidelity thermal modeling. To achieve this, development of detailed threedimensional models can be facilitated by use of the finiteelement method (FEM). Such high-fidelity models can be used to extract parameters for the real system that are then used in the simulations and the closed-loop controller. Using the transient results of the FEM, an efficient electrothermal model that closely represents the FEM and physical system can be developed to reduce computation and analysis time. This model is also an integral part of the closed-loop controller and future sensor replacement technologies (closed-loop observers) [6], [7] for junction temperature control and estimation.

\section{Active Thermal Control}

\section{A. Power Modules Thermal Failures}

Two of the main reasons for power module failures are related to overtemperature and power cycling. An overtemperature failure of the power electronic module can occur when the 


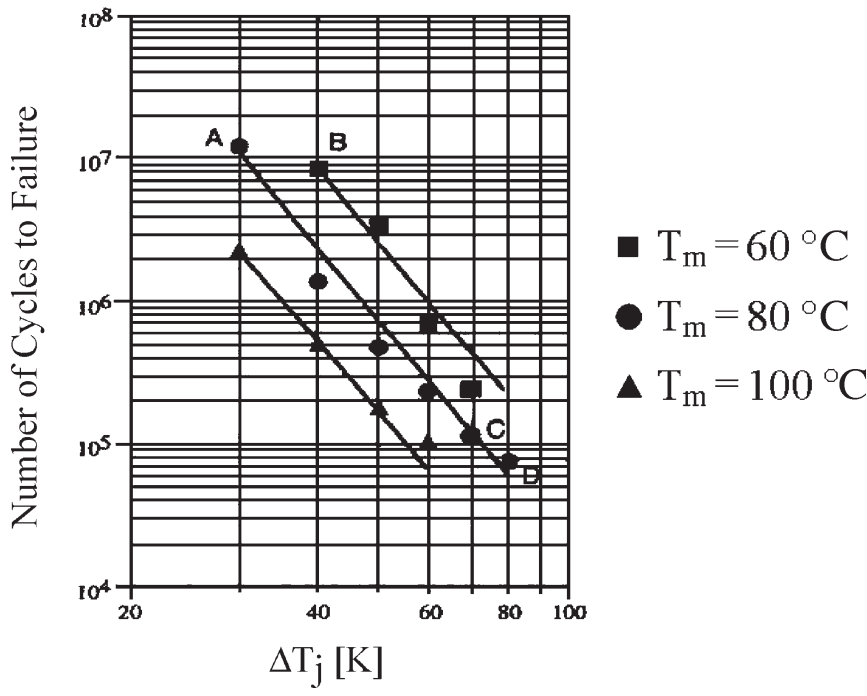

Fig. 2. Power cycling results showing the number of cycles to failure $N_{\mathrm{f}}$ as a function of $T_{\mathrm{m}}$ and $\Delta T_{j}[9]$.

module is continuously operated such that the maximum safe operating temperature of the junction is exceeded [1], [3]. In contrast, power cycling failures are the result of accumulated fatigue damage from physical stress cycles over the lifetime of the module. The wire-bond interfaces and the die-attach solder joint are prone to such failures [4]. Fig. 1 helps define the critical temperature variables that must be controlled in order to increase power module reliability in the presence of both overload-induced overtemperatures and excessive power cycling loads.

Power cycling tests usually use temporal cycling of the "average" IGBT junction, $\Delta T_{j}$, as the critical variable for wirebond and die-attach interfaces for thermal-mechanical stress levels. Moreover, proper control of $\Delta T_{j}$ improves reliability two to five times more effectively than $T_{\mathrm{m}}$, since $\Delta T_{j}$ is more closely related to the life span of the module than the mean temperature $T_{\mathrm{m}}$ [5]. Fig. 2 shows the established power cycling characteristics relating $T_{\mathrm{m}}$ to both overtemperature and power cycling limits.

Due to the strong relationship between the mean temperature $T_{\mathrm{m}}$ and the change in temperature $\Delta T_{j}$ to overtemperature and power cycling failures, a region-based controller designed to regulate these two variables was implemented to mitigate the thermal-mechanical stresses and protect the die from overtemperature and power cycling failures.

\section{B. Region-Based Controller for Active Thermal Control}

This section briefly summarizes the work done in [5] to achieve active thermal control of IGBT power modules. Fig. 3 shows the relationship between switching frequency and output current to power loss in the module at a junction temperature of $125\left\lceil^{\circ} \mathrm{C}\right\rceil$.

From this information, it is possible to see that by manipulating these two variables, we can control the amplitude of the loss and therefore regulate the temperature inside of the module [3]. It is also possible to use adjustable turn-on and turn-off rates for

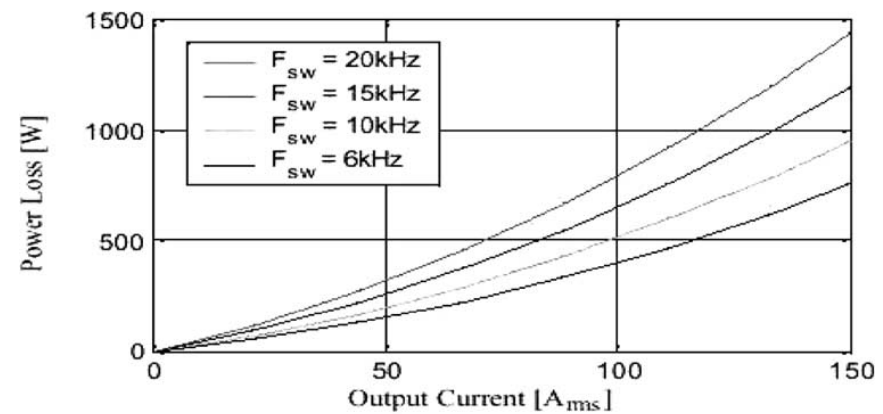

(a)

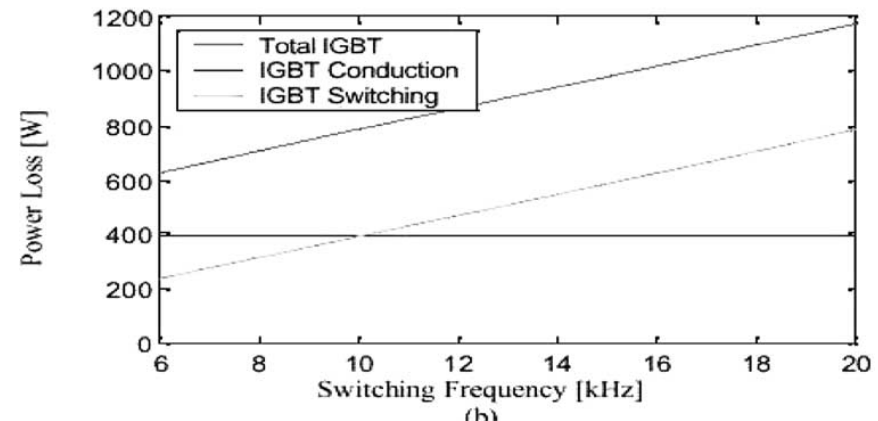

(b)

Fig. 3. Impact of (a) output current and (b) switching frequency on IGBT module power loss [5].

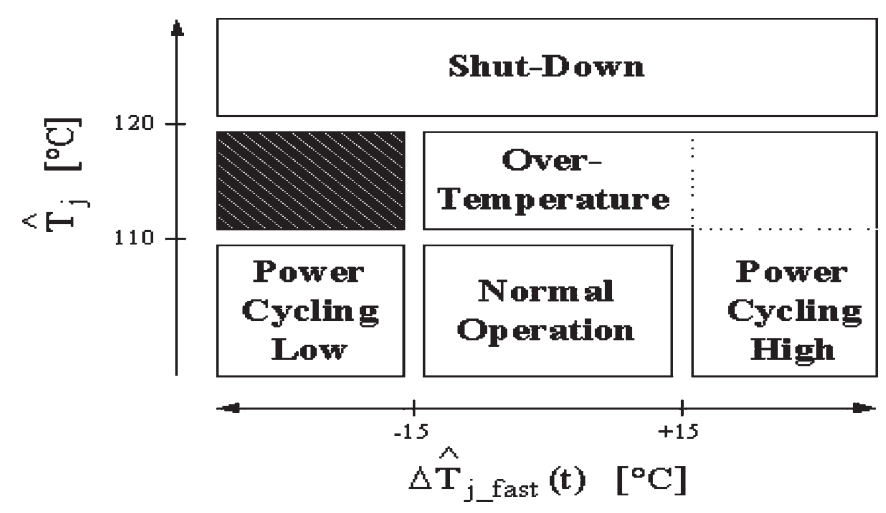

Fig. 4. Region definitions for region-based active thermal controller.

voltage and current as viable methods for controlling the device losses during operation.

The region-based controller (a design-oriented variant of fuzzy logic) is divided into regional sets that define the different thermal operating modes (see Fig. 4). The first set of regions contains the normal operation region, overtemperature region, and the shutdown region. This regional set is based on the mean operating temperature and protects the module from overtemperature failures. The second set of regions contains the power cycling high region and power cycling low region. This regional set is based on the change in measured junction temperature $\Delta T_{j}$ and protects the module from power cycling failures.

In the normal operation region, the current limit is set at two times the nominal current, and the switching frequency is set to the nominal design value (i.e., $15 \mathrm{kHz}$ for the laboratory system).

The overtemperature region is defined as the region when the temperature of the module exceeds the nominal operating 


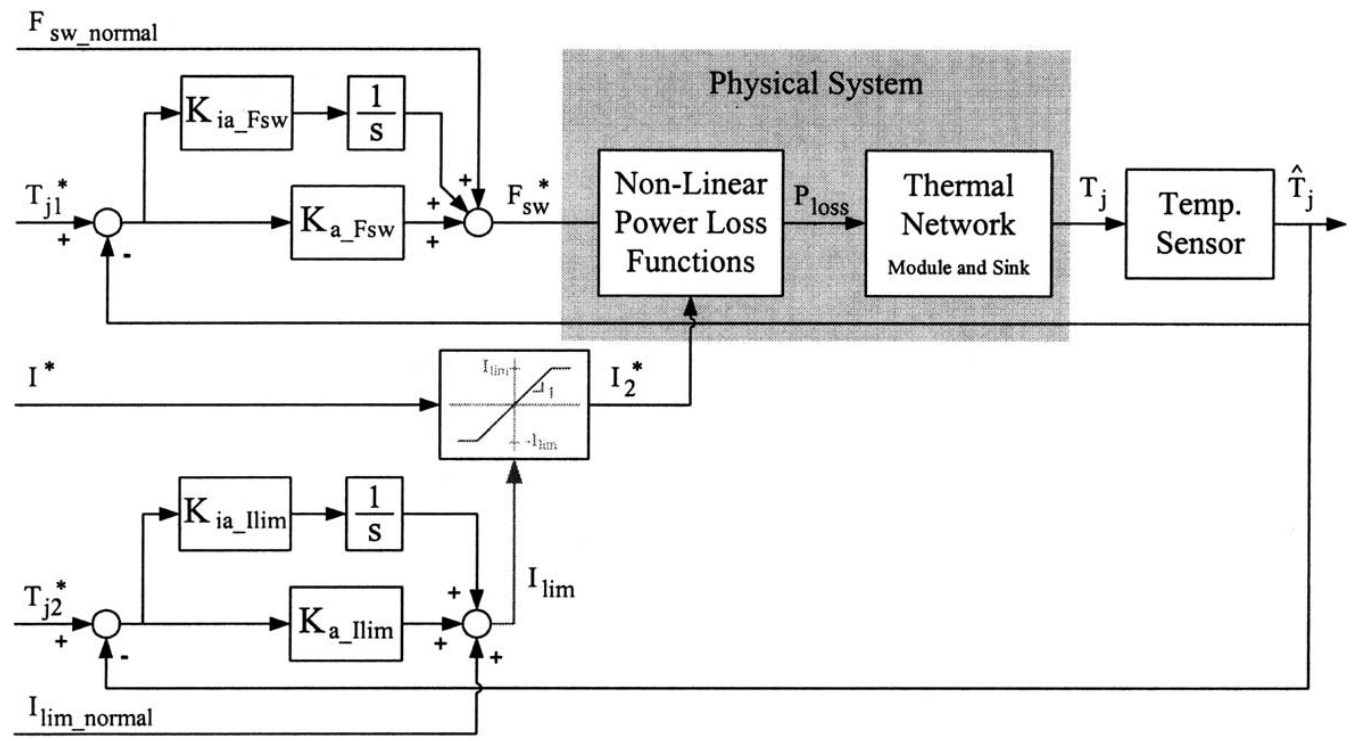

Fig. 5. Block diagram of controller implemented for the overtemperature region [5] (where $F_{\text {sw_normal }}=15 \mathrm{kHz}, I_{\text {lim_normal }}=120 \mathrm{~A}_{\mathrm{rms}}, T_{j 1}^{*}=108^{\circ} \mathrm{C}$, $T_{j 2}^{*}=110^{\circ} \mathrm{C}$, and $I^{*}$ is the commanded load current).

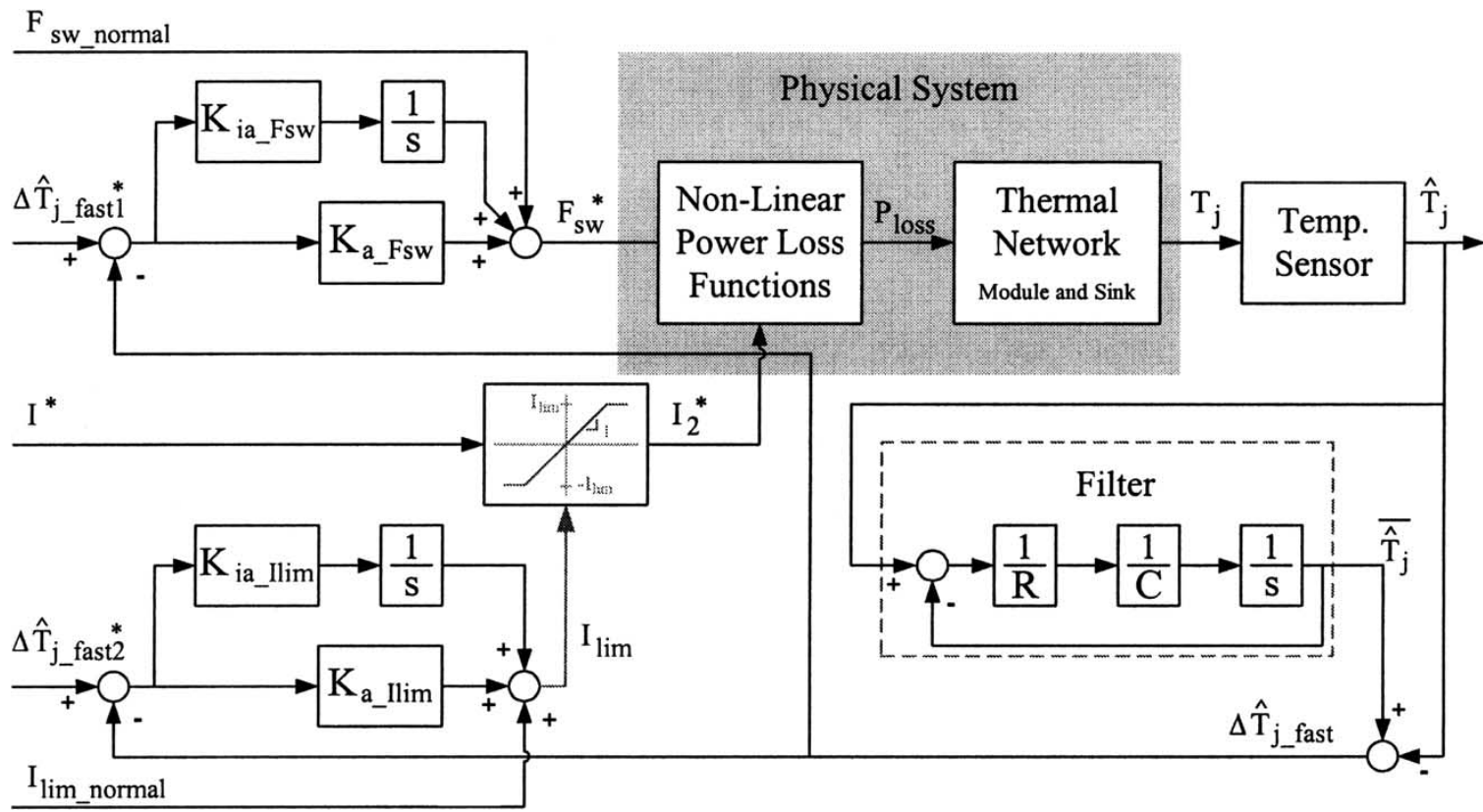

Fig. 6. Block diagram of the controller implanted in the power cycling high region [5]. The same topology applies to the power cycling low region (where $F_{\text {sw_normal }}=15 \mathrm{kHz}, I_{\text {lim_normal }}=120 \mathrm{~A}_{\mathrm{rms}}, \Delta \hat{T}_{j_{-} \text {fast } 1}=13^{\circ} \mathrm{C}, \Delta \hat{T}_{j_{-} \text {fast } 2}^{*}=15^{\circ} \mathrm{C}$, and $I^{*}$ is the commanded load current).

temperature limit, approximately $110{ }^{\circ} \mathrm{C}$. The controller was designed with two proportional-integral (PI) regulators to reduce the switching frequency and current in order to prevent the junction temperature from rising above $110{ }^{\circ} \mathrm{C}$. Fig. 5 shows the block diagram associated with the overtemperature region of the controller. A small temperature difference between the switching frequency and the current limit controller is selected to reduce the switching frequency first and then reduce the output current to minimize the impact on the load.

The shutdown region was designed to protect the drive from overtemperature conditions that result from extreme operating conditions. The control law turns off the drive output when the minimum switching frequency and minimum current limit have both been reached and the measured temperature exceeds $120^{\circ} \mathrm{C}$.

To increase the thermal space of the power cycling controller, power cycling high and power cycling low controls laws were implemented.

The power cycling high controller is activated when $\Delta \hat{T}_{j_{-} \text {fast }}$ is above its limit based on the device characteristics as shown in Fig. 2 (set at $+15^{\circ} \mathrm{C}$ in the laboratory system). The lower limit for the current is set based on minimum acceptable performance limits of the drive. In the laboratory system, this lower bound has been set to $1.0 \mathrm{pu}\left(60 \mathrm{~A}_{\mathrm{rms}}\right)$, ensuring that minimum current can be guaranteed from the drive unless it is a risk of an immediate failure from overtemperature conditions. 

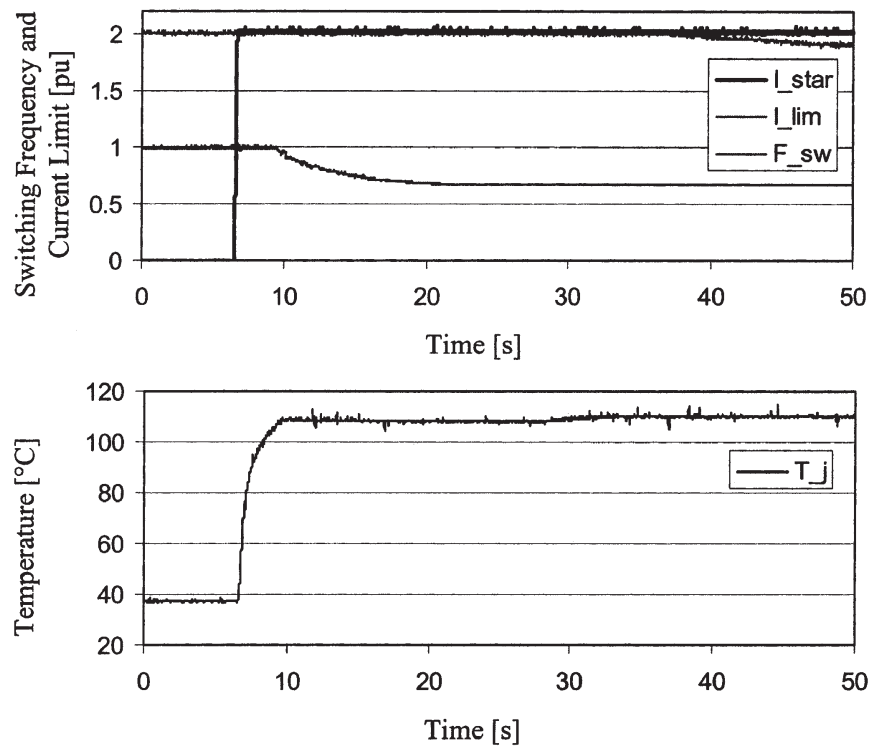

Fig. 7. IGBT junction temperature response to an extended current command of twice rated current with overtemperature region control laws implemented [5] (where $T_{j}$ is the measured junction temperature $\hat{T}_{j}, F_{\mathrm{sw}}$ is the switching frequency, $I_{\mathrm{lim}}$ is the current limit, and $I_{\mathrm{star}}$ is the current command; base values: $I_{\text {base }}=60 \mathrm{~A}_{\text {rms }}$ and $F_{\text {sw_base }}=15 \mathrm{kHz}$ )

Negative deviations in $\Delta \hat{T}_{j_{-} \text {fast }}$, below $-15{ }^{\circ} \mathrm{C}$, activate the power cycling low region when the load demand decreases. Consequently, there is no benefit from increasing the current limit in this region. The switching frequency is manipulated by a PI control loop with a controller using a topology similar to Fig. 6.

During implementation of the power cycling control laws, two factors limited the generation of suitable state variables. One is the dependency of $\Delta \hat{T}_{j}$ on load cycle period and the second is the practical limitations related to calculation of the mean junction temperature $\hat{T}_{\mathrm{m}}$. To address these limitations, power cycling control is divided into two parts. The fast dynamics are regulated by controlling the measured junction temperature $\hat{T}_{j}$ relative to its average value $\hat{T}_{j}$. The average junction temperature $\hat{T}_{j}$ equals the mean temperature for sufficiently fast load cycles.

The temporal differential is controlled during fast load changes. The instantaneous power cycling temperature difference is controlled during fast load changes and is given by the following equation (in degrees Celsius): $\Delta \hat{T}_{j_{-} \text {fast }}=\hat{T}_{j}-$ $\hat{T}_{j}$. To increase the reliability and maintain consistency with the power cycling reliability data, $\Delta \hat{T}_{j_{-} \text {fast }}$ was regulated between $+15{ }^{\circ} \mathrm{C}$ and $-15{ }^{\circ} \mathrm{C}$, which makes a total of $30{ }^{\circ} \mathrm{C}$ for $\Delta T_{j}$. In order to allow variations in $\hat{T}_{j}$ during slow load changes, a slow thermal filter was modeled as a first-order lowpass resistance-capacitance $(R C)$ network. Proper selection of the $R C$ constant in the $\hat{T}_{j}$ filter can produce $\Delta T_{j}$ that guarantees the useful life of the power module for at least ten years.

\section{Region-Based Controller Experimental Results}

The experimental results were obtained using an AllenBradley 1336 frame with a 150-A 1200-V Fuji Semiconductor IGBT [8]. An Analog Devices thermocouple interface board
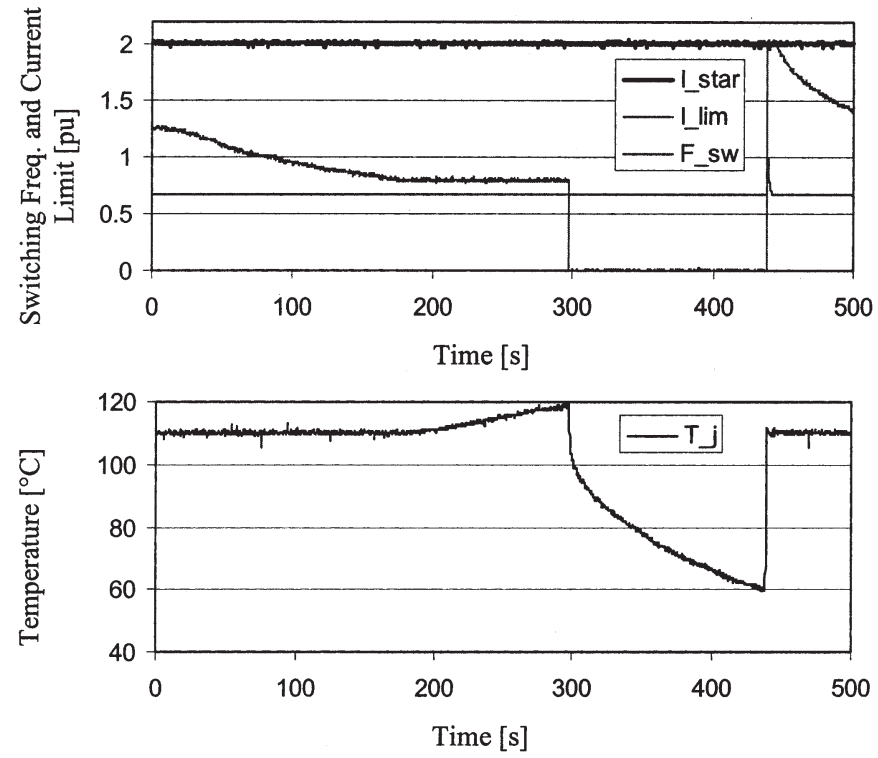

Fig. 8. IGBT junction temperature response to a fan failure with overtemperature region control laws implemented [5] (base values: $I_{\text {base }}=60 \mathrm{~A}_{\text {rms }}$ and $F_{\text {sw_base }}=15 \mathrm{kHz}$ ).

and isolated thermocouple amplifier module (5B47-J-02) were used in conjunction with a microthermocouple mounted on the top surface of the IGBT to obtain the junction temperature of the IGBT in the power module [9]-[11]. The thermocouple isolation module has a built-in 4-Hz low-pass filter. Although this filtering was helpful in reducing the electromagnetic interference (EMI) noise levels on the signals, the controller performance is limited. Ideally, a clean high-bandwidth junction temperature sensor would be required to achieve full protection. The region-based control laws were implemented using an Analog Devices digital signal processor (DSP) [11].

As discussed previously, two groups of regions for temperature control of the power electronic module were implemented. Fig. 7 shows the results for overtemperature control of the IGBT temperature.

The normal operating region corresponds to the time before the junction temperature rises to $108{ }^{\circ} \mathrm{C}$. After the measured temperature reaches $108^{\circ} \mathrm{C}$, the overtemperature region control laws reduce the switching frequency and clamp $\hat{T}_{j}$ at $108{ }^{\circ} \mathrm{C}$. If the measured junction temperature rises above $110{ }^{\circ} \mathrm{C}$ after the switching frequency reaches the lower bound of $10 \mathrm{kHz}$, the current limit successfully maintains $\hat{T}_{j}$ at $110^{\circ} \mathrm{C}$. Fig. 8 verifies the shutdown function of the overtemperature controller during a simulated fan failure condition. It is observed that almost immediately after the fan shutdown, the overtemperature region controller reduces the current limit to keep the temperature below $110^{\circ} \mathrm{C}$. At around $200 \mathrm{~s}$, the current limit reaches a lower limit (about $0.75 \mathrm{pu}$ ) and the junction temperature begins to rise. The region-based controller switches to the shutdown region when $\hat{T}_{j}$ reaches $120^{\circ} \mathrm{C}$. After shutdown, the current limit is set at $0 \mathrm{~A}$ and the IGBT cools to $60^{\circ} \mathrm{C}$, which allows the system to go back online.

The experimental results for the power cycling control laws are illustrated in Fig. 9. A balanced load cycle with a current command of $90 \mathrm{~A}_{\mathrm{rms}}$ for $50 \%$ of the time and $20 \mathrm{~A}_{\mathrm{rms}}$ for 

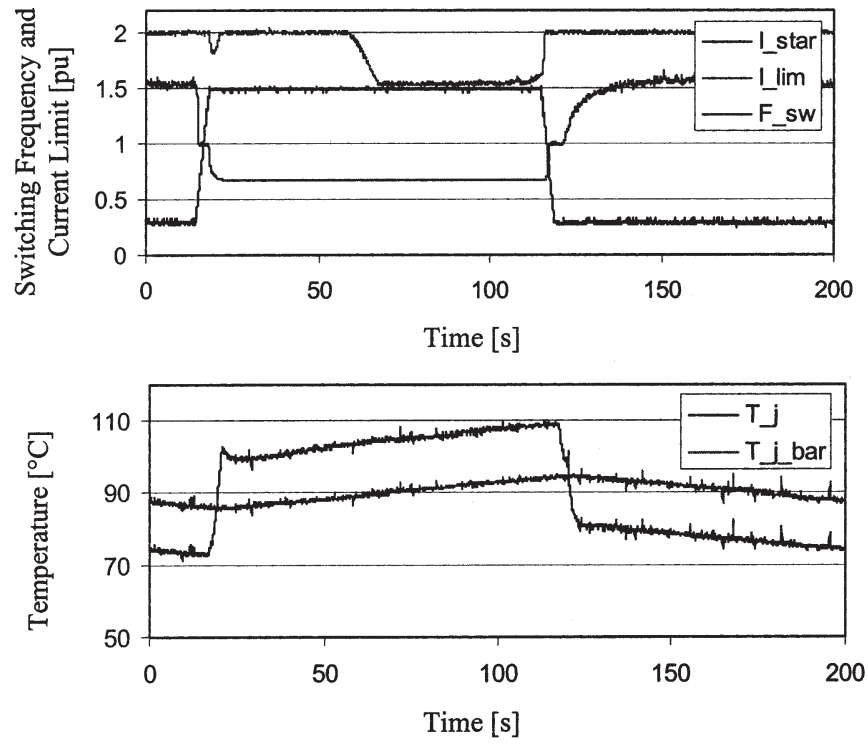

Fig. 9. Performance of the power cycling control laws for a 200-s period load cycle [5] (where $\hat{T}_{j}$ is the measured junction temperature $\hat{T}_{j}, \hat{T}_{j \_ \text {bar }}$, is the average junction temperature $\hat{T}_{j}, F_{\mathrm{sw}}$ is the switching frequency, $I_{\text {lim }}$ is the current limit, and $I_{\text {star }}$ is the current command; base values: $I_{\text {base }}=60 \mathrm{~A}_{\mathrm{rms}}$ and $F_{\text {sw_base }}=15 \mathrm{kHz}$ ).
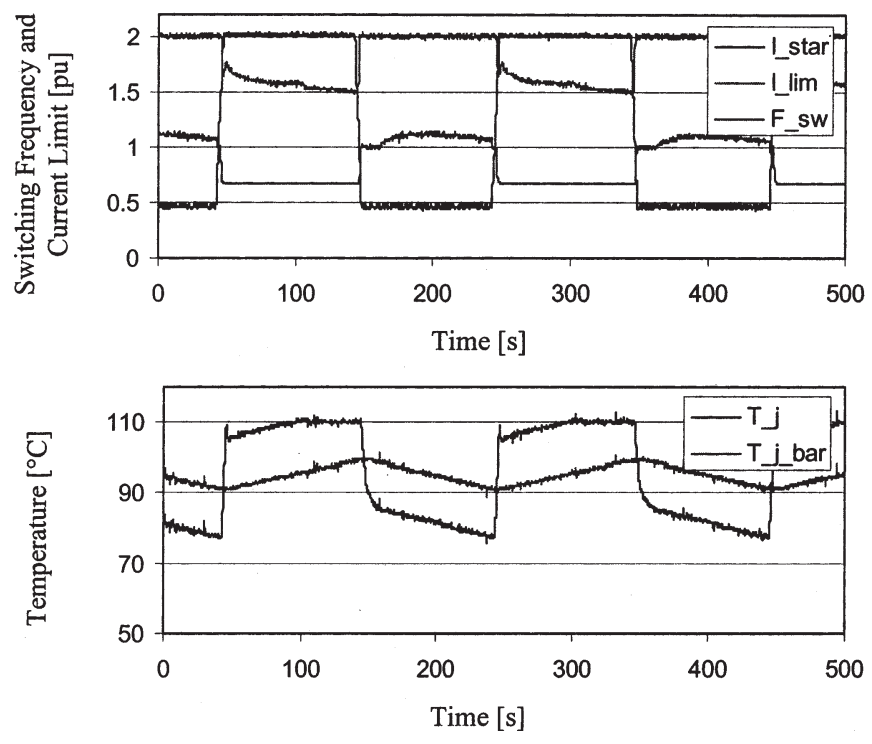

Fig. 10. Performance of the power cycling and overtemperature control laws for a 200-s period load cycle [5] (base values: $I_{\text {base }}=60 \mathrm{~A}_{\mathrm{rms}}$ and $F_{\mathrm{sw}}$ base $=$ $15 \mathrm{kHz})$.

$50 \%$ for the other half of the time was applied to the power electronic module. The $\Delta \hat{T}_{j \text { fast }}$ control in the power cycling high and power cycling low regions work properly. It is observed that $\hat{T}_{j}$ stays within $\pm 15^{\circ} \mathrm{C}$ of $\hat{T}_{j}$ over the cycle.

The compatibility between the power cycling high and overtemperature regions is shown in Fig. 10 toward the later portion of the ON pulse where the controller transitions smoothly from the power cycling high region to the overtemperature region.

From the figure, it was determined that the total change in junction temperature $\Delta \hat{T}_{j}$ for the load cycle is approximately $32{ }^{\circ} \mathrm{C}$; which is more conservative than the target value of $37^{\circ} \mathrm{C}$ presented in [1].

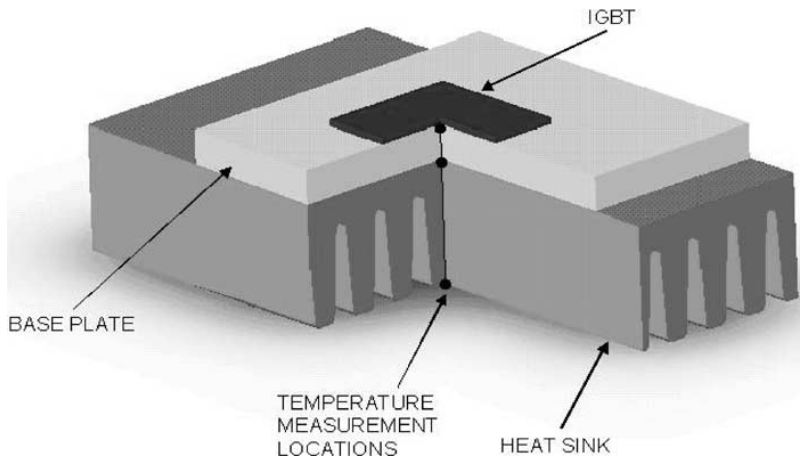

Fig. 11. Representative FEA model for simplified power module.

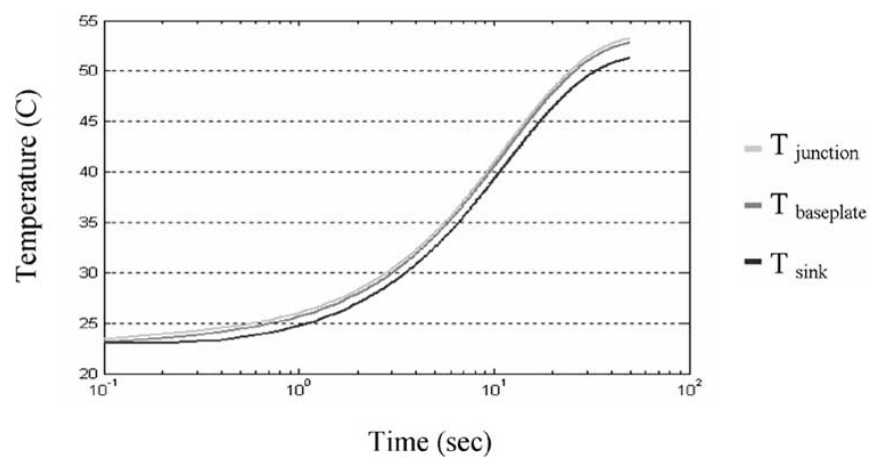

Fig. 12. Typical temperature versus time results from the ANSYS model.

The experimental results demonstrated the ability of the control laws to actively control the thermal operating levels of the power electronics module. The performance of the regionbased controller was also demonstrated in the different regions of the thermal operating space and showed an expected increase in the reliability of the power modules to at least ten years of power cycling operation [2], [3], [12].

\section{Finite-Element Analysis (FEA)}

Finite element analysis provides estimated temperature information about the internal layers of the power module structure that are otherwise immeasurable yet necessary for calculating lumped parameter values of each layer. A simplified three-layer FEM model was developed for transient thermal analysis of the silicon power devices based on the higher fidelity model created in [5]. This higher fidelity model is based on the geometry and boundary conditions present in the experimental test setup using an Allen-Bradley 1336 frame ac drive in which a single-phase leg Fuji power module is mounted to a large heat sink that is cooled through natural or forced air convection. For modeling purposes, the bottom surface of the heat sink was assigned a constant heat transfer coefficient that was experimentally determined in [5]. A constant thermal flux of $103 \mathrm{~W} / \mathrm{m}^{2}$, also experimentally determined in [5], was assigned to the upper active surface of the IGBT. Fig. 11 illustrates the three layers that were modeled and the three locations selected to monitor temperature.

As a starting point, the lumped parameter values are determined for the three-layer model for initial testing and simulation of the observer capabilities as a sensor replacement 


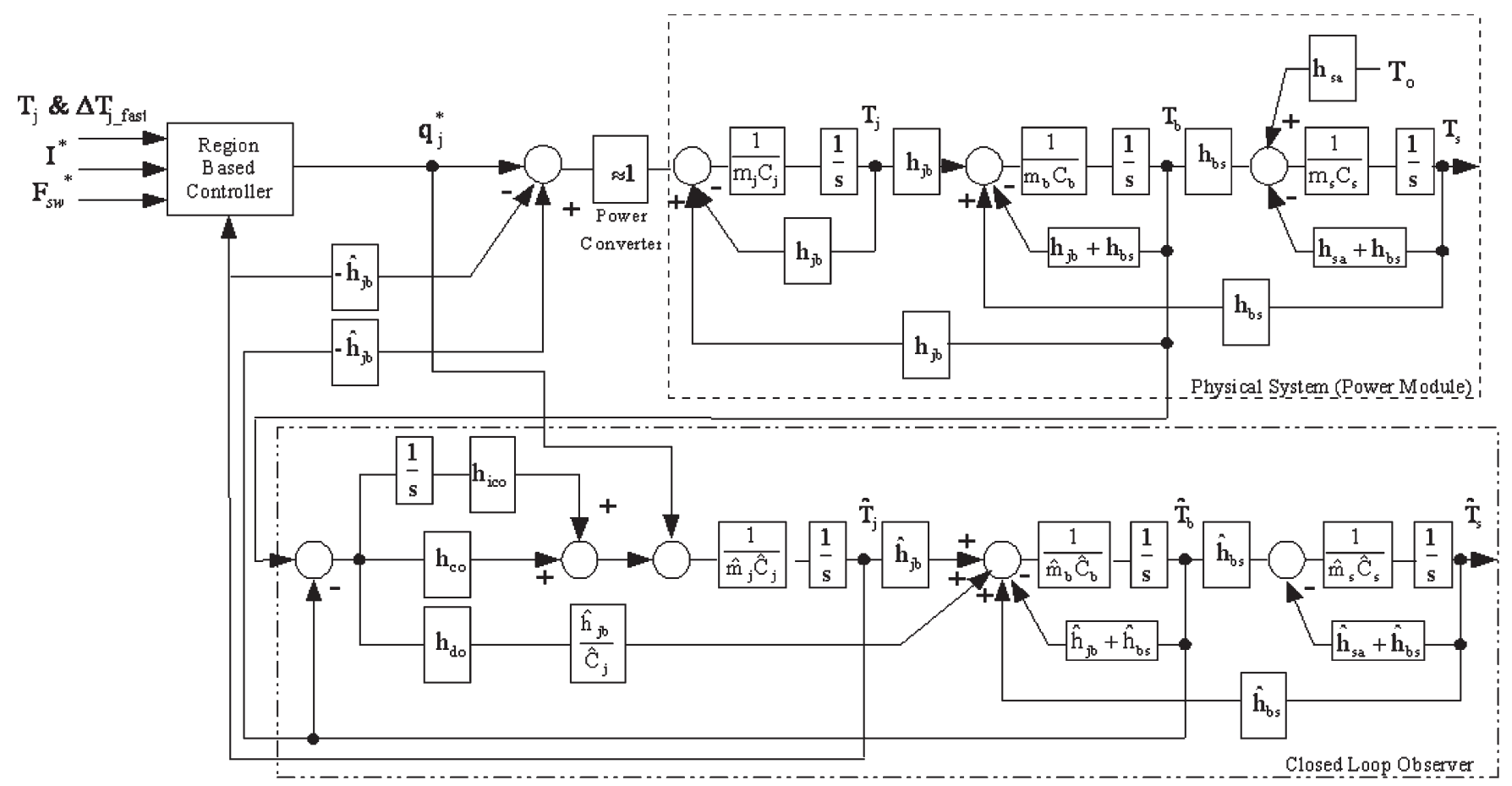

Fig. 13. Observer structure for a simplified three-layer model.

technology. Eventually, this technique will be expanded to include a more detailed model of the power module structure to include all of the layers present in typical integrated power modules.

Under the conditions previously listed, the transient thermal response of the simplified system was analyzed with the ANSYS FEM software. The results from this transient thermal analysis (Fig. 12) are used to develop the resistance, capacitance, and propagation delay terms used in the resistor/ capacitor component model (RCCM) as in [13].

The resulting resistance and capacitance values of the reduced-order system can then be included in the observer model. Fig. 13 shows the general structure of the three-layer observer structure including the physical system and estimated parameter values for the observer model.

This technology can then be used as a sensor replacement technique for estimating junction temperature using a baseplate temperature sensor in the module.

\section{CONCLUSION AND Future WORK}

This paper has presented the development and evaluation of active thermal control algorithms designed to protect the power module from overtemperature and power cycling failures as well as to increase utilization of the full thermal capacity of the silicon. It was demonstrated that by controlling the thermal operating performance of the module, it is possible to obtain optimal utilization of the semiconductor die while simultaneously mitigating thermal-mechanical mean and cyclical stresses, thus leading to an expected increase in the reliability of the power modules.

The experimental results showed that the region-based controller is well suited for the defined operating thermal space. It protects the power module from overtemperature and power cycling failures resulting from sustained operation at the physical limits of the power electronic module.

A new approach for junction temperature estimation is currently being investigated using an enhanced-Luenberger-style closed-loop observer. This new technology will be used to replace the actual temperature sensor at the junction used to provide temperature information for the region-based controller. Closed-loop observers are expected to provide accurate junction temperature estimates (with reduced noise effects) for feedback signals to the new active thermal control algorithms in development.

\section{REFERENCES}

[1] M. Ciappa and W. Fichtner, "Lifetime prediction of IGBT modules for traction applications," in Proc. IEEE Int. Reliability Physics Symp., San Jose, CA, 2000, pp. 210-216.

[2] V. A. Sankaran, C. Chen, C. S. Avant, and X. Xu, "Power cycling reliability of IGBT power modules," in Conf. Rec. IEEE-IAS Annu. Meeting, New Orleans, LA, Oct. 5-9, 1997, pp. 1222-1227.

[3] V. Blasko, R. Lukaszewski, and R. Sladky, "Online thermal model and thermal management strategy of a three phase voltage source inverter," in Conf. Rec. IEEE-IAS Annu. Meeting, Phoenix, AZ, Oct. 1999, pp. 1423 1431.

[4] J. He, V. Mehrotra, and M. C. Shaw, "Thermal design and measurements of IGBT power modules: Transient and steady state," in Conf. Rec. IEEEIAS Annu. Meeting, Phoenix, AZ, Oct. 1999, pp. 1440-1444.

[5] D. A. Murdock, "Active thermal control of power electronic modules," M.S. thesis, Dept. Elect. Comput. Eng., Univ. Wisconsin, Madison, 2002.

[6] N. Y. A. Sharmas, M. P. Rodriguez, A. T. Plumpton, and D. Newcombe, "Finite element modeling of thermal fatigue effects in IGBT modules," Proc. Inst Elect. Eng.—Circuits Devices Syst., vol. 148, no. 2, pp. 95-100, Apr. 2001.

[7] P. E. Bagnoli, C. Casarosa, E. Dallago, and M. Nardoni, "Thermal resistance analysis by induced transient method for power electronic devices: Thermal characterization - Part I: Fundamentals and theory," IEEE Trans. Power Electron, vol. 13, no. 6, pp. 1208-1219, Nov. 1998. 
[8] Fuji Semiconductor Data Sheet, 2MBI150NB-120 2-Pack IGBT, $150 \mathrm{~A}, 1200 \mathrm{~V}$. [Online]. Available: http://www.fujisemiconductor.com/ index $2 . \mathrm{html}$

[9] M. Held, P. Jacob, G. Nicoletti, P. Scacco, and M.-H. Poech, "Fast power cycling test for IGBT modules in traction application," in Proc. IEEE Power Electronics and Drive Systems Conf., Singapore, 1997, vol. 1, pp. $425-430$.

[10] Analog Devices, The 5B Series User's Manual. Pub. G111420-2/90.

[11] Analog Devices Data Sheet, Single-Chip, DSP-Based High Performance Motor Controller, AMDC401. [Online]. Available: http://www. analog.com

[12] P. Jacob, M. Held, P. Scacco, and W. Wu, "Reliability testing and analysis of IGBT power semiconductor modules," in IEE Colloq. IGBT Propulsion Drives, London, U.K., 1995, pp. 4/1-4/5.

[13] C.-S. Yun, P. Malberti, M. Ciappa, and W. Fichtner, "Thermal component model for electromechanical analysis of IGBT module systems," IEEE Trans. Adv. Packag., vol. 24, no. 3, pp. 401-405, Aug. 2001.

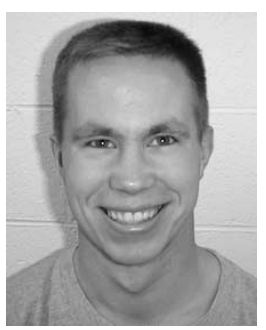

Dustin A. Murdock received the B.S. degree in electrical and computer engineering and the M.S. degree in electrical engineering from the University of Wisconsin, Madison, in 1999 and 2002, respectively.

He is currently with the Development Department, Powercorp Pty. Ltd., Darwin, Australia.

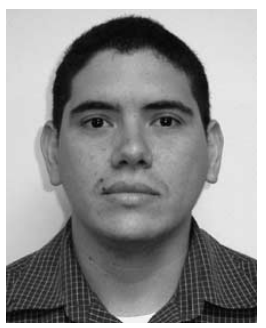

Jose E. Ramos Torres (S'99-M'00) received the B.S. and M.S. degrees in electrical engineering from the University of Puerto Rico, Mayaguez, in 1999 and 2001, respectively.

$\mathrm{He}$ joined the faculty of the University of Puerto Rico as a Teaching Assistant in the Electrical and Computer Engineering Department, also in 2001 Some of the courses he taught include controls systems, basic circuits, and electric machines. He has published three IEEE technical papers jointly with his academic advisors during his research. His research has involved optimization of the useful life of power electronic modules by controlling and estimating several variables using observers and controllers. In addition, he was an active member of the Center for Power Electronics Systems (CPES), which is a five-university research group. He is currently a Project Engineer (Automation and Controls Engineer) with Cooper Vision, Juana Diaz, PR, a manufacturer of contact lenses. His work is strongly related to automation and controls of different stages during installation of new machinery and control support once the manufacturing process has begun.

Mr. Torres is a Licensed Engineer in Puerto Rico. He is a member of "Colegio de Ingenieros y Agrimensores de Puerto Rico." He is a member of Golden Key and Tau Beta Pi.

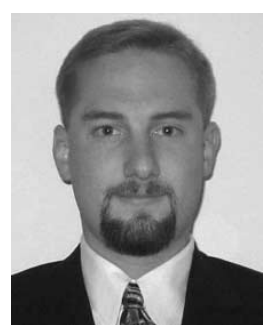

Jeffrey J. Connors was born in Albuquerque, NM, in 1976. He received the B.S. degree in mechanical engineering from the New Mexico Institute of Mining and Technology, Socorro, and the M.S. degree in mechanical engineering from the University of Wisconsin, Madison, in 1999 and 2004, respectively.

$\mathrm{He}$ is currently with Omnitech Robotics, Englewood, $\mathrm{CO}$. His interests include the design, fabrication, and testing of prototype electromechanical devices for aerospace and industrial applications.

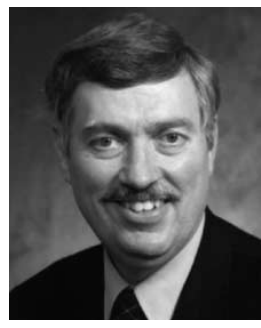

Robert D. Lorenz (S'83-M'84-SM'91-F'98) received the B.S. degree in mechanical engineering, and the M.S. and Ph.D. degrees in controls engineering from the University of Wisconsin, Madison, and the M.B.A. degree from the University of Rochester, Rochester, NY.

Since 1984, he has been a member of the Faculty of the University of Wisconsin, Madison, where he is the Mead Witter Foundation Consolidated Papers Professor of Controls Engineering in both the Department of Mechanical Engineering and the Department of Electrical and Computer Engineering. He is a Co-Director of the Wisconsin Electric Machines and Power Electronics Consortium, which celebrated its 20th anniversary in 2001. It is the largest industrial research consortium on motor drives and power electronics in the world. He is also the Thrust Leader for Control and Sensor Integration in the Center for Power Electronic Systems, an NSF Engineering Research Center, which is a joint ERC with Virgina Polytechnic Institute, Rensselaer Polytechnic Institute, University of Puerto Rico-Mayaguez, and North Carolina A\&T. From 1972 to 1982 , he was a member of the Research Staff at Gleason Works, Rochester, NY, working principally on high-performance drives and synchronized motion control. He was a Visiting Research Professor in the Electrical Drives Group of the Catholic University of Leuven, Leuven, Belgium, in the summer of 1989 and in the Power Electronics and Electrical Drives Institute of the Technical University of Aachen, Aachen, Germany, in the summers of 1987, 1991, 1995, 1997, and 1999 and was the SEW Eurodrive Guest Professor from September 1, 2000, until July 7, 2001. In 1969-1970, he did his Master thesis research in adaptive control of machine tools at the Technical University of Aachen. His current research interests include sensorless electromagnetic motor/actuator technologies, real-time signal processing and estimation techniques, precision multiaxis motion control, and alternating current/direct current $(\mathrm{ac} / \mathrm{dc})$ drive and high-precision machine control technologies. He has authored more than 170 published technical papers and is the holder of 21 patents, with three more pending.

Dr. Lorenz is a Registered Professional Engineer in the States of New York and Wisconsin. He is a member of the American Society of Mechanical Engineers, the Instrument Society of America, and the International Society for Optical Engineers. He is the IEEE Division II Director for 2005/2006, was the IEEE Industry Applications Society (IAS) President for 2001, a Distinguished Lecturer of the IEEE IAS for 2000/2001, the past Chair of the IAS Awards Department, the past Chairman of the IAS Industrial Drives Committee, and is a member of the IAS Industrial Drives Committee, Electrical Machines Committee, Industrial Power Converter Committee, and Industrial Automation and Control Committee. He is the immediate past Chair of the Periodical Committee and the current Chair of the Periodicals Review Committee for the IEEE Technical Activities Board. He is a member of the IEEE Sensor Council AdCom. He received the 2003 IEEE IAS Outstanding Achievement Award, which honors his outstanding contributions and technological developments in the application of electricity to industry. He has won 19 Prize Paper Awards. 